\title{
Increasing risk of Amazonian drought due to decreasing aerosol pollution
}

\author{
Peter M. Cox ${ }^{1,2}$, Phil P. Harris ${ }^{3}$, Chris Huntingford ${ }^{3}$, Richard A. Betts ${ }^{2}$, Matthew Collins ${ }^{2}$, Chris D. Jones ${ }^{2}$, Tim E. Jupp ${ }^{1}$, \\ José A. Marengo ${ }^{4} \&$ Carlos A. Nobre ${ }^{4}$
}

The Amazon rainforest plays a crucial role in the climate system, helping to drive atmospheric circulations in the tropics by absorbing energy and recycling about half of the rainfall that falls on it. This region (Amazonia) is also estimated to contain about onetenth of the total carbon stored in land ecosystems, and to account for one-tenth of global, net primary productivity ${ }^{1}$. The resilience of the forest to the combined pressures of deforestation and global warming is therefore of great concern ${ }^{2}$, especially as some general circulation models (GCMs) predict a severe drying of Amazonia in the twenty-first century ${ }^{3-5}$. Here we analyse these climate projections with reference to the 2005 drought in western Amazonia, which was associated ${ }^{6}$ with unusually warm North Atlantic sea surface temperatures (SSTs). We show that reduction of dryseason (July-October) rainfall in western Amazonia correlates well with an index of the north-south SST gradient across the equatorial Atlantic (the 'Atlantic N-S gradient'). Our climate model is unusual among current GCMs in that it is able to reproduce this relationship and also the observed twentieth-century multidecadal variability in the Atlantic N-S gradient ${ }^{7}$, provided that the effects of aerosols are included in the model ${ }^{8}$. Simulations for the twenty-first century using the same model ${ }^{3,8}$ show a strong tendency for the SST conditions associated with the 2005 drought to become much more common, owing to continuing reductions in reflective aerosol pollution in the Northern Hemisphere?

In 2005 large areas of the Amazon river basin experienced one of the most intense drought episodes of the last 100 years $^{6}$. The drought most directly affected western Amazonia, and especially the catchments of the Solimões and the Madeiras rivers. Navigation along these major tributaries had to be suspended because the water levels were so low. Unlike during the El Niño-related droughts in 1926, 1983 and 1997, central and eastern Amazonia were not directly affected, although river levels on the Rio Negro in central Amazonia did reach unusually low levels in October 2005, owing to reduced inflow from the tributaries to the west.

Rainfall in Amazonia is sensitive to seasonal, interannual and decadal variations in SSTs ${ }^{7,10,11}$. The warming of the tropical East Pacific during El Niño events suppresses wet-season rainfall through modification of the (east-west) Walker circulation and via the Northern Hemisphere extratropics ${ }^{12}$. El Niño-like climate change $e^{13}$ has similarly been shown to influence the annual mean rainfall over South America in GCM climate-change projections ${ }^{4,5}$.

However, variations in Amazonian precipitation are also known to be linked to SSTs in the tropical Atlantic ${ }^{11}$. A warming of the tropical Atlantic in the north relative to the south leads to a northwestwards shift in the intertropical convergence zone and compensating atmospheric descent over Amazonia ${ }^{10}$. For northeast Brazil the relationship between the north-south Atlantic SST gradient and rainfall is sufficiently strong to form the basis for a seasonal forecasting system ${ }^{14}$. Here we show that Atlantic SSTs exert a large influence on dryseason rainfall in western Amazonia by delaying onset of the South American monsoon ${ }^{15,16}$.

July to October 2005 was associated with a persistent warm anomaly in the North Atlantic ${ }^{17}$ centred on latitudes $10-15^{\circ} \mathrm{N}$, and a weaker cold anomaly in the South Atlantic at around latitude $15^{\circ} \mathrm{S}$ (Fig. 1). The absence of a warming in the tropical East Pacific implies that El Niño was in a near-neutral state and therefore did not contribute to the 2005 drought. The black box over land in Fig. 1 denotes the western Amazonian area chosen for the purposes of this study $\left(75^{\circ} \mathrm{W}-60^{\circ} \mathrm{W}, 12^{\circ} \mathrm{S}-0^{\circ}\right)$. The black boxes over ocean show the northern $\left(15^{\circ} \mathrm{N}-35^{\circ} \mathrm{N}, 75^{\circ} \mathrm{W}-30^{\circ} \mathrm{W}\right)$ and southern $\left(25^{\circ} \mathrm{S}-5^{\circ} \mathrm{S}\right.$, $\left.40^{\circ} \mathrm{W}-5^{\circ} \mathrm{E}\right)$ regions used to calculate an index of the Atlantic N-S gradient (ANSG). These areas were chosen for comparability with the GCM climate projections that we present below, but are also nearoptimal on the basis of a statistical analysis using observations alone ${ }^{18}$.

We analyse results from the HadCM3LC coupled climate-carboncycle model ${ }^{4}$, which is based upon the Met Office Hadley Centre's third-generation ocean-atmosphere GCM, HadCM $3^{19}$. This is one of only three current, global climate models that fit within the observational limits on the July-October western Amazonian rainfall and the ANSG (see Supplementary Information). The HadCM3 model has also performed well in GCM intercomparison exercises and was recently recognized to be one of two GCMs that simulate the Amazonian climate with reasonable accuracy ${ }^{5}$. HadCM3LC in addition includes dynamic vegetation and an interactive carbon cycle,

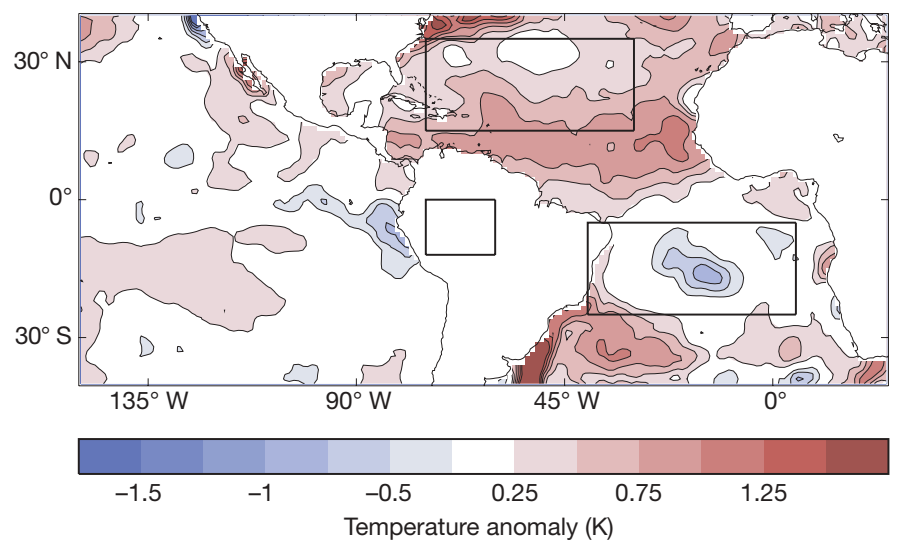

Figure 1 | Anomalies in SSTs for July-October 2005, relative to the July-October mean values over the standard climatological period 1961-1990. The black boxes show the regions used in this study. 
meaning that atmospheric $\mathrm{CO}_{2}$ concentrations can be updated on the basis of anthropogenic emissions, taking into account the effects of climate change on ocean and land $\mathrm{CO}_{2}$ uptake.

We consider two separate simulations using HadCM3LC for the period from 1860 to 2100 (refs 4, 8). In both cases the model is driven with $\mathrm{CO}_{2}$ emissions consistent with the IS92a scenario, which is approximately in the centre of the spread of future emissions represented by the results of the more recent Special Report on Emissions Scenarios $^{20}$. Both model experiments also include prescribed timevarying concentrations of trace greenhouse gases $\left(\mathrm{CH}_{4}, \mathrm{~N}_{2} \mathrm{O}\right)$ based on the IS92a scenario. The second run additionally includes changes in tropospheric and stratospheric ozone, solar variability and, most notably, forcing due to sulphate and volcanic aerosols. This model experiment was able to reproduce the observed warming and $\mathrm{CO}_{2}$ increase over the twentieth century to good accuracy, especially when we used a revised estimate of the net $\mathrm{CO}_{2}$ flux from land-use change (run 'ALL70' from ref. 8).

We compared the results of these simulations with observations of the ANSG index ${ }^{17}$ and rainfall in western Amazonia ${ }^{21}$ for the twentieth century, using 20-yr running means in each case (Fig. 2). The 2005 ANSG index value of $4.92 \mathrm{~K}$ was exceeded regularly during the 1930s, 1940s and 1950s, but has not reached such a high value since 1960. There is significant variability in the 20-yr-mean ANSG index (which is much larger than the standard deviation of the annualmean values), with values declining from around 1960 to the mid1980s before increasing in the past two decades. This variation is mirrored by the 20-yr mean western Amazonian rainfall measurements, which decreased from the 1920s to 1960 and then increased until the mid-1980s before decreasing again to the values observed today.

Both HadCM3LC simulations capture the observed inverse relationship between the ANSG index and July-October precipitation in the western Amazon. However, the simulation with greenhouse gases only (Fig. 2, red lines) fails to reproduce the observed decadal variability in the ANSG index (the correlation coefficient between the 20yr running means of observed and modelled ANSGs is -0.75), and instead predicts a near-monotonic increase in the ANSG index and a corresponding near-monotonic decrease in western Amazonian rainfall from the mid-twentieth century onwards. On the other hand,
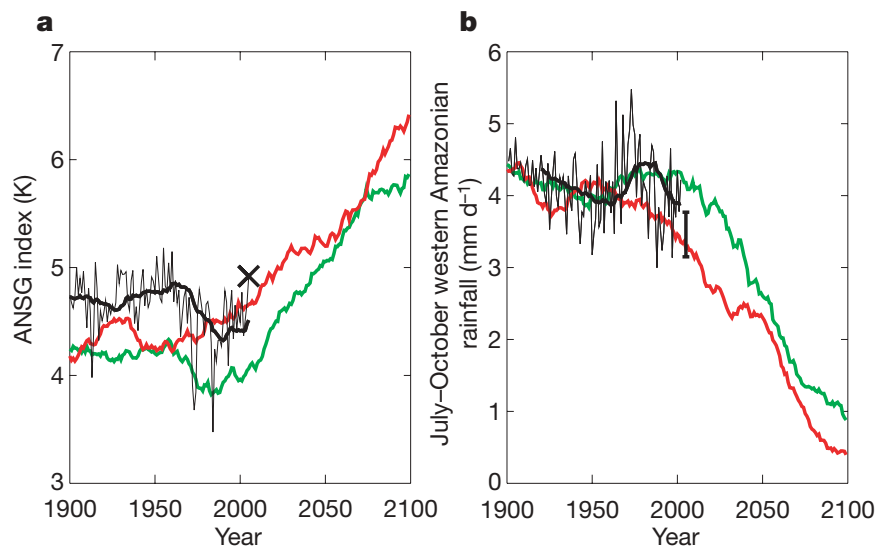

Figure 2 | Comparison of observed and modelled climate variables relevant to the Amazonian drought of 2005. Evolution of July-October mean values of $\mathbf{a}$, the ANSG index; $\mathbf{b}$, rainfall in western Amazonia. Observations are shown in black ${ }^{17,20}$, with the thin lines corresponding to annual values and the thick lines showing 20 -yr running means. The other lines show $20-\mathrm{yr}$ running means from the HadCM3LC GCM. The red line corresponds to a simulation of climate change driven by greenhouse gas increases only ${ }^{3}$, whereas the green line additionally includes changes in aerosols, stratospheric and tropospheric ozone, and revised fluxes of $\mathrm{CO}_{2}$ from landuse change ${ }^{8}$. The large cross in $\mathbf{a}$ and the bar in $\mathbf{b}$ show the estimated values for July-October 2005. the HadCM3LC run with aerosols (Fig. 2, green lines) produces a good fit to the multi-decadal variation in the ANSG index (the correlation coefficient between the 20 -yr running means is in this case +0.82 ), and reproduces the observed decrease in 20-yr mean western Amazonian rainfall from the 1920s to 1960 .

This suggests that longer-term variations in the ANSG, and associated effects on Amazonian rainfall, are as much a consequence of forced variability as they are of internal variability. Furthermore, the two model runs taken together indicate that non-greenhouse-gas forcing, primarily from anthropogenic and volcanic aerosols, has acted to suppress the development of a stronger ANSG, and thereby delayed the suppression of dry-season rainfall in the western Amazon. It seems that reflective sulphate aerosol pollution produced in the Northern Hemisphere may have helped to maintain rainfall in South America, just as it may have contributed to the Sahelian droughts of the 1970s and $1980 \mathrm{~s}^{22}$.

The HadCM3LC model also produces a realistic correlation between interannual variations in the western Amazonian rainfall and the ANSG index (Fig. 3). The best-fit straight lines linking these variables for the model and the observations are very nearly parallel, having respective gradients of $-0.65 \pm 0.29$ and $-0.58 \pm$ $0.46 \mathrm{~mm} \mathrm{~d}^{-1} \mathrm{~K}^{-1}$ (throughout the paper we quote error bars as \pm 2 s.d. giving approximately $95 \%$ confidence limits). The HadCM3LC model validates best among current GCMs in this respect (see Supplementary Information). For the twenty-first century, the model predicts a strengthening of the relationship between the (decreasing) western Amazonian rainfall for the July-October period and the (increasing) ANSG index, as indicated by the quadratic best-fit shown in Fig. 3 .

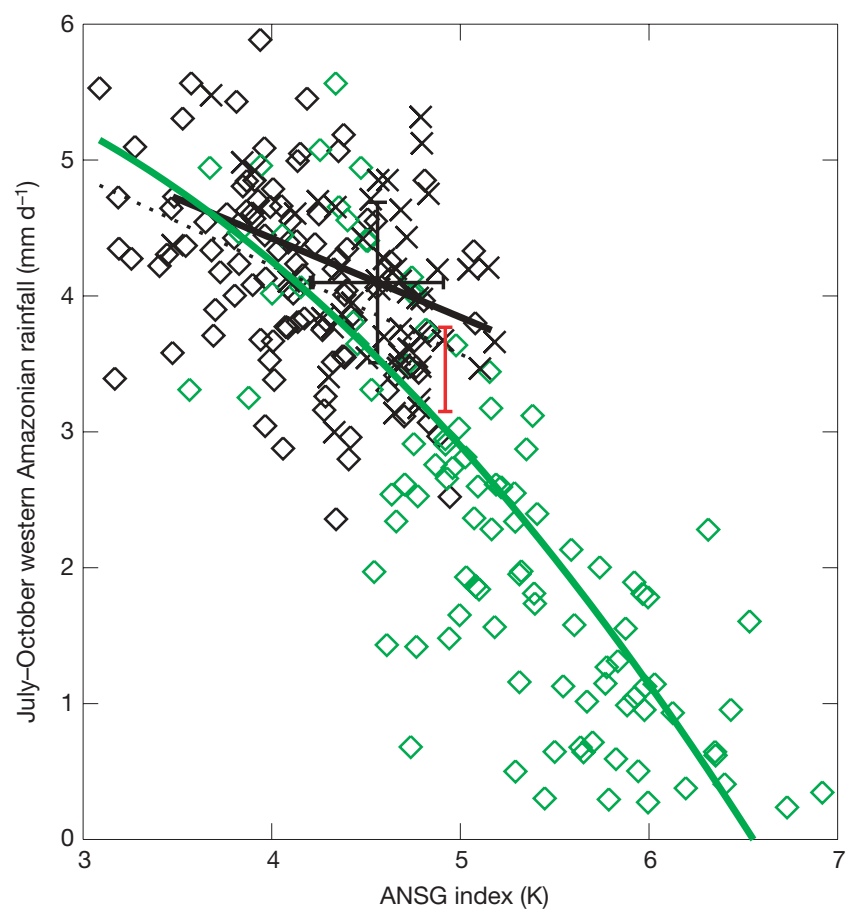

Figure 3 | Relationship between the July-October mean values of western Amazonian rainfall and the ANSG index. Observations for the period 1901-2002 are plotted with black crosses ${ }^{17,20}$. Model output from the HadCM3LC GCM run with aerosols ${ }^{8}$ is plotted with black diamonds for the historical period (1901-2002) and with green diamonds for the simulation of the twenty-first century (2003-2100). The black lines are the best-fit straight lines to the observations (1950-1999; solid) and the twentieth-century simulation (1900-1999; dashed). The green line is the best quadratic fit to the entire GCM simulation (1860-2099). The large black cross shows the mean and standard deviation of the observations, and the red bar shows the range of estimated values for the 2005 Amazon drought. 
Our simulations suggest that the North Atlantic region will warm more rapidly than the South Atlantic in the future, leading to a northwards movement of the intertropical convergence zone and suppression of July-October rainfall in western Amazonia. Aerosol pollution has occurred predominantly in the industrialised north, which tends to suppress the development of this north-south warming gradient. However, as air quality improves, aerosol cooling of the climate is expected to decrease ${ }^{9}$, potentially revealing a larger ANSG. This is evident in the HadCM3LC run with aerosols (Fig. 2, green lines), which predicts a $2 \mathrm{~K}$ increase in the ANSG index by the end of the twenty-first century. As a consequence, this GCM projection suggests that the conditions of 2005 will be experienced more and more frequently as atmospheric greenhouse gas concentrations increase and sulphur dioxide emissions decrease in the Northern Hemisphere (see Supplementary Information).

Climate model projections are known to differ markedly with respect to regional rainfall changes over Amazonia, but a comparison of the results from 20 GCMs included in the Fourth Assessment Report of the Intergovernmental Panel on Climate Change reveals two robust features: there is a cross-model relationship between the twenty-first-century trends in western Amazonian rainfall and the twenty-first-century trends in the ANSG index, which is consistent with the observed interannual variability in these variables; and models that include aerosol forcing tend to predict greater increases in the ANSG index in the first few decades of the twenty-first century (see Supplementary Fig. S3). Taken together, these findings support our basic conclusion that aerosol forcing has delayed reductions in Amazonian rainfall but is unlikely to do so for much longer.

We estimated the probability of a '2005-like' year occurring in the HadCM3LC run with aerosols, based on the fraction of years in a centred 20-yr window that exceed the ANSG index for 2005 (Fig. 4). The model suggests that 2005 was an approximately 1 -in-20-yr event, but will become a 1 -in-2-yr event by 2025 and a 9 -in-10-yr event by 2060. These thresholds obviously depend on the rate of increase of $\mathrm{CO}_{2}$, which is itself dependent on the emissions scenario chosen. Figure $4 \mathrm{~b}$ shows how the probability of a 2005-like event increases as a function of $\mathrm{CO}_{2}$ concentration in this HadCM3LC model, with the $50 \%$ probability level exceeded at about 450 p.p.m.v. and the $90 \%$ probability level exceeded at around 610 p.p.m.v. These results suggest a rapidly increasing risk of 2005-like droughts in Amazonia under conditions of reduced aerosol loading and increased greenhouse gases.
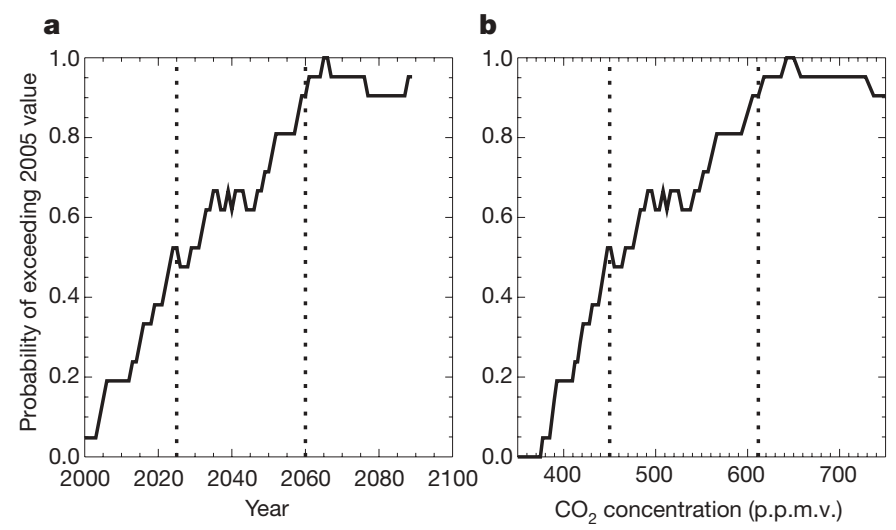

Figure 4 | Predicted change in the probability of a 2005-like drought in Amazonia, based on results from the HadCM3LC GCM run with aerosols ${ }^{8}$. Probabilities are calculated as the fraction of years that exceed the July-October 2005 anomaly in the ANSG index, using the 20-yr window centred on each year: $\mathbf{a}$, probability versus year; $\mathbf{b}$, probability versus simulated $\mathrm{CO}_{2}$ concentration. The dotted lines respectively mark the points beyond which the 2005 anomaly is exceeded in $50 \%$ of the simulated years $\left(2025,450\right.$ p.p.m.v. of $\left.\mathrm{CO}_{2}\right)$ and in $90 \%$ of the simulated years $(2060$, 610 p.p.m.v. of $\mathrm{CO}_{2}$ ).

\section{METHODS SUMMARY}

The climate model used was HadCM3LC - a version of HadCM $3{ }^{19}$ that includes an interactive carbon cycle ${ }^{3}$. Two model runs were carried out: one with greenhouse gases only ${ }^{3}$, and one with greenhouse gases plus other key climate forcing factors including anthropogenic sulphate aerosols ${ }^{8}$. In both runs, atmospheric $\mathrm{CO}_{2}$ concentration was modelled interactively by specifying emissions taken from the IS92a scenario and allowing the carbon-cycle model to partition these between oceanic, terrestrial and atmospheric carbon pools. Non- $\mathrm{CO}_{2}$ greenhouse gases were prescribed to follow a standard IS92a concentration scenario ${ }^{3}$. The 'aerosol run' also included revised net $\mathrm{CO}_{2}$ emissions from land use, solar variability, tropospheric and stratospheric ozone changes, and the climatic effects of volcanic and anthropogenic aerosols ${ }^{8}$.

To investigate the relative importance of Atlantic and Pacific SST variabilities for Amazonian rainfall, we constructed SST indices from the Hadley Centre's HadISST data set ${ }^{17}$. The Pacific index was defined as the SST difference between the equatorial West Pacific $\left(5^{\circ} \mathrm{S}-5^{\circ} \mathrm{N}, 120^{\circ} \mathrm{E}-180^{\circ} \mathrm{E}\right)$ and the Niño-3 region $\left(5^{\circ} \mathrm{S}-5^{\circ} \mathrm{N}, 150^{\circ} \mathrm{W}-90^{\circ} \mathrm{W}\right)$ to remove the impacts of global warming. The Atlantic index used was the ANSG index, defined as the SST difference between the tropical North Atlantic $\left(15^{\circ} \mathrm{N}-35^{\circ} \mathrm{N}, 75^{\circ} \mathrm{W}-30^{\circ} \mathrm{W}\right)$ and the tropical South Atlantic $\left(25^{\circ} \mathrm{S}-5^{\circ} \mathrm{S}, 40^{\circ} \mathrm{W}-15^{\circ} \mathrm{E}\right)$. Time series of precipitation from the Climatic Research Unit ${ }^{21}$ (CRU TS 2.0) were calculated for western Amazonia $\left(75^{\circ} \mathrm{W}-60^{\circ} \mathrm{W}, 12^{\circ} \mathrm{S}-0^{\circ}\right)$. Linear regression analyses were carried out to determine the relative sensitivity of the western Amazonian rainfall to the Atlantic and Pacific SST indices. Rainfall in the dry season (July-October) was found to be correlated with variability in the ANSG index, with no significant dependence on the east-west Pacific SST gradient ${ }^{16}$. This analysis therefore allowed us to focus on the Atlantic SST anomalies when seeking to understand the Amazonian drought of July-October 2005.

Full Methods and any associated references are available in the online version of the paper at www.nature.com/nature.

\section{Received 23 January; accepted 3 April 2008.}

1. Melillo, J. M. et al. Global climate change and terrestrial net primary production. Nature 363, 234-240 (1993).

2. Tian, H. et al. Climatic and biotic controls on annual carbon storage in Amazonian ecosystems. Glob. Ecol. Biogeogr. 9, 315-335 (2000).

3. Cox, P. M., Betts, R. A., Jones, C. D., Spall, S. A. \& Totterdell, I. J. Acceleration of global warming due to carbon cycle feedbacks in a coupled climate model. Nature 408, 184-187 (2000).

4. Cox, P. M. et al. Amazon dieback under climate-carbon cycle projections for the 21st century. Theor. Appl. Climatol. 78, 137-156 (2004).

5. Li, W., Fu, R. \& Dickinson, R. E. Rainfall and its seasonality over the Amazon in the $21 s t$ century as assessed by the coupled models for the IPCC AR4. J. Geophys. Res. 111, D02111 (2006).

6. Marengo, J. A. et al. The drought of Amazonia in 2005. J. Clim. 21, 495-516 (2008).

7. Marengo, J. A. Interdecadal variability and trends of rainfall across the Amazon basin. Theor. Appl. Climatol. 78, 79-96 (2004).

8. Jones, C. D., Cox, P. M., Essery, R. L. H., Roberts, D. L. \& Woodage, M. Strong carbon cycle feedbacks in a climate model with interactive $\mathrm{CO}_{2}$ and sulphate aerosols. Geophys. Res. Lett. 30, doi:10.1029/2003GL016867 (2003).

9. Andreae, M. O., Jones, C. J. \& Cox, P. M. Strong present-day aerosol cooling implies a hot future. Nature 435, 1187-1190 (2005).

10. Fu, R., Dickinson, R. E., Chen, M. X. \& Wang, H. How do tropical sea surface temperatures influence the seasonal distribution of precipitation in the equatorial Amazon? J. Clim. 14, 4003-4026 (2001).

11. Liebmann, B. \& Marengo, J. Interannual variability of the rainy season and rainfall in the Brazilian Amazon basin. J. Clim. 14, 4308-4318 (2001).

12. Nobre, P. \& Shukla, J. Variations of sea surface temperature, wind stress and rainfall over the tropical Atlantic and South America. J. Clim. 9, 2464-2479 (1996)

13. Meehl, G. A. \& Washington, W. M. El Nino-like climate change in a model with increased atmospheric $\mathrm{CO}_{2}$ concentrations. Nature 382, 56-60 (1996).

14. Folland, C. K., Colman, A. W., Rowell, D. P. \& Davey, M. K. Predictability of Northeast Brazil rainfall and real-time forecast skill 1987-1998. J. Clim. 14, 1937-1958 (2001).

15. Marengo, J. A., Liebmann, B., Kousky, V. E., Filizola, N. P. \& Wainer, I. C. Onset and end of the rainy season in the Brazilian Amazon Basin. J. Clim. 14, 833-852 (2001).

16. Harris, P., P, Huntingford C. \& Cox, P. M. Amazon Basin climate under global warming: the role of the sea surface temperature. Phil. Trans. R. Soc. B 363, 1753-1759 (2008).

17. Rayner, N. A. et al. Global analyses of sea surface temperature, sea ice, and night marine air temperature since the late nineteenth century. J. Geophy. Res. 108, doi:10.1029/2002JD002670 (2003).

18. Good, P., Lowe, J., Collins, M. \& Moufouma-Okia, W. An objective tropical Atlantic sea surface temperature gradient index for studies of South Amazon 
dry-season climate variability and change. Phil. Trans. R. Soc. B 363, 1761-1766 (2008).

19. Gordon, C. et al. Simulation of SST, sea ice extents and ocean heat transports in a version of the Hadley Centre coupled model without flux adjustments. Clim. Dyn $16,147-168$ (2000).

20. Nakicenovic, N. et al. Special Report on Emissions Scenarios, Summary for Policy Makers (Intergovernmental Panel on Climate Change, Geneva, Switzerland, 2000).

21. New, M., Hulme, M. \& Jones, P. Representing twentieth-century space-time climate variability. Part II: Development of 1901-96 monthly grids of terrestrial surface climate. J. Clim. 13, 2217-2238 (2000).

22. Rotstayn, L. D. \& Lohmann, U. Tropical rainfall trends and the indirect aerosol effect. J. Clim. 15, 2103-2116 (2002).

Supplementary Information is linked to the online version of the paper at www.nature.com/nature.

Acknowledgements The authors acknowledge funding from the NERC CLASSIC programme and Great Western Research (P.M.C. and T.E.J.); the CEH Science Budget (C.H. and P.P.H.); the UK Department for Environment, Food and Rural Affairs and the UK Ministry of Defence (R.A.B, C.D.J. and M.C.); and the Brazilian
Research Council and the Global Opportunities Fund from the UK Foreign and Commonwealth Office (C.A.N. and J.A.M.). We also acknowledge the modelling groups the Program for Climate Model Diagnosis and Intercomparison and the WCRP Working Group on Coupled Modelling for their roles in making available the WCRP CMIP3 multimodel data set. Support for this data set is provided by the Office of Science, US Department of Energy.

Author Contributions P.M.C. coordinated the work, identified the role of aerosols in delaying Amazonian drying in HadCM3LC, and drafted the paper; P.P.H. and C.H. defined the SST indices and analysed the relationships between these indices and western Amazonian rainfall, in both the observations and the model runs; C.D.J. and R.A.B. carried out the HadCM 3 LC runs and provided output data from them; J.A.M. and C.A.N. provided observational data and insights on the nature of the 2005 drought in western Amazonia; M.C. extracted and then intercompared data on predicted changes in Amazonia from the CMIP3 models; C.H. and T.E.J. provided guidance on statistical significance.

Author Information Reprints and permissions information is available at www.nature.com/reprints. Correspondence and requests for materials should be addressed to P.M.C. (p.m.cox@exeter.ac.uk). 


\section{METHODS}

Climate simulations. The climate model used was HadCM3LC - a version of HadCM $3^{19}$, but with a slightly lower ocean resolution $\left(2.5^{\circ}\right.$ latitude by $3.75^{\circ}$ longitude), which is necessary because of the extra computational expense of the oceanic carbon-cycle model. As a result, the model requires the use of flux corrections. The HadCM3LC model includes interactive terrestrial and oceanic carbon-cycle components. The terrestrial carbon-cycle model, TRIFFID, is a dynamic global vegetation model, which models carbon allocation between five competing plant functional types and a soil carbon reservoir ${ }^{23}$. The oceanic carbon-cycle model, HadOCC, includes a representation of oceanic chemistry and biology ${ }^{24}$.

In both model runs, atmospheric $\mathrm{CO}_{2}$ concentration was modelled interactively and non- $\mathrm{CO}_{2}$ greenhouse gases were prescribed to follow a standard IS92a concentration scenario ${ }^{3}$. The aerosol run also included the following six features ${ }^{8}$.

The direct effect of anthropogenic sulphate aerosols was calculated using an interactive sulphur-cycle scheme $e^{25}$, driven by historic anthropogenic sulphur dioxide emissions and twenty-first-century anthropogenic emissions according to the A2 scenario from the Special Report on Emissions Scenarios ${ }^{20}$. Dry deposition was calculated separately for each of the five vegetation types in each grid box, using $\mathrm{CO}_{2}$-dependent canopy resistance values calculated according to the MOSES-2 land-surface scheme ${ }^{26}$.

The first indirect effect of anthropogenic sulphate (that is, the cloud albedo effect) was included using a non-interactive method in which cloud albedo perturbations are imposed on the basis of output from a set of preliminary sulphur-cycle runs ${ }^{25}$.

Climate forcing due to volcanic eruptions was represented by specifying the stratospheric aerosol distribution up to present day ${ }^{27}$, and assuming that it is zero thereafter.

Tropospheric and stratospheric ozone changes were prescribed on the basis of results from the atmospheric chemistry model STOCHEM ${ }^{28}$.

Solar forcing up to present day was taken from a reconstruction of solar irradiances $^{29}$, and kept constant (equal to the mean of the last 11 years) after 2000.

Revised net $\mathrm{CO}_{2}$ emissions from land-use change ${ }^{8}$ were used.

23. Cox, P. M. Description of the "TRIFFID" dynamic global vegetation model. Technical Note 24 (Met Office Hadley Centre, UK, 2001); 〈http://www.metoffice.gov.uk/ research/hadleycentre/pubs/HCTN/HCTN_24.pdf).

24. Palmer, J. R. \& Totterdell, I. J. Production and export in a global ocean ecosystem model. Deep-Sea Res. I 48, 1169-1198 (2001).

25. Johns, T. C. et al. Anthropogenic climate change for 1860 to 2100 simulated with the HadCM3 model under updated emissions scenarios. Clim. Dyn. 20, 583-612 (2003).

26. Essery, R. L. H., Best, M. J., Betts, R. A., Cox, P. M. \& Taylor, C. M. Explicit representation of sub-grid heterogeneity in a GCM land-surface scheme. J. Hydrometeorol. 4, 530-543 (2003).

27. Sato, M., Hansen, J. E., McCormick, M. P. \& Pollack, J. B. Stratospheric aerosol optical depths (1850-1990). J. Geophys. Res. 98, 22987-22994 (1993).

28. Stevenson, D. S., Johnson, C. E., Collins, W. J., Derwent, R. G. \& Edwards, J. M. Future estimates of tropospheric ozone radiative forcing and methane turnover: The impact of climate change. Geophys. Res. Lett. 27, 2073-2076 (2000).

29. Lean, J., Beer, J. \& Bradley, R. Reconstruction of solar irradiance since 1610: Implications for climate change. Geophys. Res. Lett. 22, 3195-3198 (1995). 